\title{
AFETIVIDADE E FORMAÇÃO DO EDUCADOR MUSICAL
}

\author{
Affectivity and music teacher's education
}

\author{
Afectividad y formación del educador \\ musical
}

\author{
Silvia CoRdeiro Nassif \\ Universidade Estadual de Campinas \\ scnassif@unicamp.br
}

\begin{abstract}
Resumo: Este artigo apresenta uma pesquisa em andamento sobre um curso de licenciatura em música, cujo objetivo principal é investigar os percursos curriculares dos alunos na perspectiva dos próprios estudantes e com foco nas questões afetivas. Tendo como principal fundamento a teoria histórico-cultural, assume-se a indissociabilidade entre afeto e cognição nos processos de aprendizagem. A partir de dados coletados através de questionários e entrevistas, o recorte aqui apresentado enfatiza alguns aspectos em relação à pluralidade de perfis musicais do corpo discente na instituição investigada e à maneira como essa diversidade é levada em conta ou não no curso. A principal consideração destacada a partir da análise conduz à importância de que as singularidades musicais dos estudantes sejam efetivamente contempladas de alguma forma na maneira como o currículo é posto em ação. Esse cuidado se constitui, de acordo com a análise aqui proposta, não apenas em condição sine qua non de aprendizagem musical, como também em requisito para a formação de um educador musical capaz de considerar ele mesmo, futuramente, as identidades musicais de seus alunos.
\end{abstract}

Palavras-chave: Afetividade. Formação do educador musical. Teoria histórico-cultural.

\begin{abstract}
This article presents an ongoing research on a Music Degree course. The primary objective is to investigate the students' curricular pathways from their perspectives and focused on affective issues. Taking as a theoretical reference the cultural-historical psychology, it is based on the assumption of the inseparability between affection and cognition in learning processes. From data collected through questionnaires and interviews, the research clipping presented here emphasizes some aspects regarding the plurality of musical profiles of the student body in the investigated institution and the way this diversity is considered or not in the course. The main consideration highlighted from the analysis leads to the importance that the students' musical singularities are effectively considered in some way in the curricular actions. This attention is not only a sine qua non condition of musical learning, but also a requirement to prepare music educators capable of considering themselves, in the future, the musical identities of their students.
\end{abstract}

Keywords: Affectivity. Music teacher's education. Cultural-historical theory.

Resumen: Este artículo presenta una investigación en curso sobre un programa de Licenciatura en Música, cuyo objetivo principal, es investigar las trayectorias curriculares de los alumnos desde la perspectiva de los propios estudiantes, centrándose en los aspectos afectivos. Teniendo como principal fundamento la teoría histórico-cultural, se asume la indisociabilidad entre afecto y cognición en los procesos de aprendizaje. A partir de los datos recogidos a través de cuestionarios y entrevistas, el recorte aquí presentado enfatiza algunos aspectos con relación a la pluralidad de perfiles musicales del cuerpo estudiantil en la institución investigada y la manera como esa diversidad es tenida en cuenta o no en el curso. La principal consideración destacada a partir del análisis conduce a la importancia de que las singularidades musicales de los estudiantes sean efectivamente contempladas de alguna forma en la manera como el currículo es puesto en acción. Esta premisa se constituye, de acuerdo con el análisis aquí propuesto, no solo en condición sine qua non del aprendizaje musical, sino también en requisito para la formación de un educador musical capaz de considerar por símismo, en el futuro, las identidades musicales de sus alumnos.

Palabras clave: Afectividad. Formación del educador musical. Teoría histórico-cultural. 


\section{INTRODUÇÃO}

As relações entre afetividade e educação têm sido estudadas e discutidas em trabalhos teóricos e pesquisas empíricas de diversas naturezas pelo menos desde o início do século XX. Particularmente nas últimas décadas esse tema ganhou especial importância, em grande medida devido à disseminação no campo educacional de estudos fundamentados em aportes teóricos que trazem como pressuposto que todo processo de aprendizagem passa pela relação que os sujeitos estabelecem com o objeto do conhecimento, relação essa sempre afetivamente marcada e que pode levar tanto a um crescimento no interesse por aprender quanto a um desânimo e desistência (Leite, 2012).

Particularmente no campo da educação musical, alguns estudos têm trazido contribuições em temas que tangenciam a questão da afetividade, em especial o problema da motivação (Araújo; Cavalcanti; Figueiredo, 2010; Santos; Cernev, 2019). De maneira mais indireta, trabalhos que discutem a consideração pelos gostos e interesses dos alunos (Ramalho, 2003; Ramos; Toni, 2016); a necessidade de levar em conta as relações que os estudantes estabelecem com a música (Arroyo, 2006; Reis; Duarte, 2018; Souza, 2004); bem como a importância do apoio de familiares ou mesmo dos próprios professores para a perseverança nos estudos musicais (Pinto, 2004) também podem ser considerados estudos que, de alguma forma, relacionam-se ao grande tema da afetividade.

Neste trabalho procuro dar uma contribuição a essa questão colocando como centro da discussão o ensino superior, mais especificamente a formação do educador musical. ${ }^{1}$ Tomo como ponto de partida a percepção, como docente nesse contexto, de que muitos alunos de licenciatura em música na instituição onde leciono passam por um processo de decrescente e contínuo desinteresse pelo curso ao longo dos anos de formação. Embora em muitos cursos e instituições provavelmente isso aconteça em alguma medida, eu noto que no nosso curso há uma certa regularidade nesse processo, de tal modo que na segunda metade do tempo de graduação geralmente constata-se a existência de pelo menos dois grupos entre os alunos, com diferentes e claras posturas em relação a essa perda de interesse. Num primeiro grupo estão aqueles que, um tanto decepcionados com o que é oferecido em termos curriculares, procuram se formar o mais rápido possivel e retornar aos seus projetos musicais pré-universidade; num segundo grupo podemos identificar aqueles que, também descontentes com o currículo, vão atrasando as disciplinas obrigatórias até o limite do permitido e se engajam em projetos musicais paralelos, na própria universidade ou fora. Em comum a esses dois grupos, uma quebra de expectativas e consequente insatisfação e perda de motivação em relação ao curso, pontos diretamente ligados à questão da afetividade.

\footnotetext{
1 O uso da forma masculina em um sentido genérico visa apenas deixar a leitura do texto mais fluente. Não há nenhuma intenção de reproduzir qualquer discriminação de gênero.
} 
Essas observações iniciais, tomadas em reuniões de avaliação de curso ou mesmo informalmente em conversas pessoais, levaram-me a iniciar uma pesquisa $^{2}$ cujo objetivo principal é investigar os percursos curriculares dos alunos na perspectiva dos próprios estudantes, com especial foco nas relações afetivas. Essa investigação, por sua vez, é tomada como ponto de partida para reflexões sobre o currículo e a formação do educador musical.

Numa sondagem inicial realizada através de um questionário respondido de maneira anônima por 36 alunos e que versava sobre as suas experiências musicais prévias à universidade, motivações para a escolha da carreira, percepções sobre o currículo e expectativas profissionais futuras, algumas questões se sobressaíram, sobretudo em relação aos vínculos pessoais com a música, e que dão indícios sobre possiveis pontos nevrálgicos no currículo em questão. A esses questionários seguiram-se entrevistas individuais com dez alunos e que procuraram aprofundar aspectos evidenciados na primeira sondagem. ${ }^{3}$

Correndo o risco de deixar muitas nuances individuais de lado, que ademais não são importantes neste momento, podemos sintetizar uma espécie de voz coletiva predominante, no que diz respeito ao foco deste trabalho, da seguinte forma: os alunos, em sua maioria, estabelecem em algum período da experiência pré-universidade um vínculo muito forte com a música e buscam o curso de licenciatura como uma forma de aprofundar seus conhecimentos musicais e de transformar essa paixão musical em meio de vida. Deparando-se com um currículo no qual a música não aparece do modo esperado e as oportunidades de prática musical efetiva são bastante restritas, rapidamente há um declínio naquela energia inicial que os levou ao curso, fato que resulta no quadro antes delineado.

Disparado por essa sintese inicial, capturada na análise do material empírico coletado, este texto se propõe a uma discussão sobre a questão da afetividade no contexto de formação do educador musical. Com essa proposição em mente, apresenta inicialmente alguns fundamentos teóricos da pesquisa para, em seguida, pontuar duas questões que emergiram e tornaram possivel levantar discussões curriculares sobre a graduação pesquisada.

\section{EMOÇÃO, SENTIMENTO E AFETO NA EDUCAÇÃO}

Os termos "emoção", "sentimento" e "afeto" foram usados de maneira indiscriminada pelo psicólogo bielorrusso Lev S. Vigotski, principal aporte teórico deste trabalho. Embora o autor prefira o termo "emoção", o qual predomina absoluto em sua obra, "sentimento" e "afeto" aparecem em seus textos exatamente com o mesmo sentido (Toassa, 2011). Alguns autores atuais, entretanto, de diversas áreas do conhecimento, preferem estabelecer uma clara distinção entre "emoção" e "sentimento". O neurologista

\footnotetext{
2 Pesquisa aprovada pelo Comitê de Ética em Pesquisa, CAAE 23292619.2.0000.8142.

3 Os questionários continham 31 questões, sendo 14 fechadas e 17 abertas, e constituem a principal base de dados analisada neste texto.
} 
António Damásio (1996), por exemplo, coloca a emoção no campo das reações puramente corporais/biológicas e muitas vezes socialmente perceptíveis (como, por exemplo, alterações na voz e nos estados dos músculos) e o sentimento como a percepção consciente psicológica dessas alterações numa esfera privada. Essa distinção é aceita também por pesquisadores da educação, para os quais a afetividade seria um campo mais amplo que engloba tanto o sentimento quanto a emoção (Leite, 2012). Com o intuito de me alinhar terminologicamente aos pesquisadores mais atuais, adoto neste trabalho preferencialmente o termo "afetividade", respeitando, porém, a terminologia usada por Vigotski quando estiver me referindo à obra desse autor.

Em seu texto inacabado Teoria das emoções, Vigotski (2004) faz uma análise crítica das concepções de emoção adotadas pelas psicologias da época (início do século XX), segundo ele todas fortemente marcadas por um pensamento cartesiano dualista que dividia o ser humano em corpo e mente, emoção e pensamento. O autor considerava que essa cisão constituía o principal entrave para um avanço significativo nesse campo e propunha a filosofia monista de Espinosa ${ }^{4}$ como o caminho mais promissor a seguir. De acordo com essa filosofia, o ser humano se constitui de maneira una, não sendo possivel separar o que pertence exclusivamente ao corpo e o que pertence exclusivamente à mente. Adepto de um monismo radical, Vigotski constrói toda sua teoria psicológica sobre esse fundamento, que pode ser visto tanto na sua psicologia geral quanto nos estudos experimentais de funções psicológicas especificas, como é o caso da emoção. Toda sua concepção de desenvolvimento procura integrar de modo indissociável, na constituição do ser humano, aspectos biológicos e aspectos sociais, determinantes genéticos e determinantes culturais.

Um construto teórico que expressa de maneira clara esse posicionamento monista de Vigotski é o conceito de perejivanie (termo que pode ser traduzido como "vivência"), considerada a unidade de análise de qualquer processo de desenvolvimento do ser humano, e que integra aspectos do meio e aspectos da personalidade. É através das suas vivências, as quais incluem as experiências culturais mais significativas e são sempre carregadas de emoção, que cada pessoa significa o meio de uma maneira individual e o transforma (ou não) em fonte do próprio desenvolvimento. Não há como encontrar explicações para qualquer aquisição humana, de acordo com esse pensamento, sem considerar a imbricação total de fatores internos e externos ao indivíduo. Mais do que um conceito teórico, nesse sentido, a perejivanie é proposta como uma metodologia de análise dos processos de desenvolvimento humano. Se quisermos entender como determinadas habilidades/capacidades/competências foram adquiridas por uma pessoa, teremos sempre que nos debruçar sobre o modo como essa pessoa percebeu, foi afetada e significou o meio. Novamente

\footnotetext{
4 Baruch de Espinosa (1632-1677), filósofo considerado por alguns estudiosos um precursor da filosofia materialista (Toassa, 2011), um dos fundamentos do pensamento de Vigotski. A fonte principal do materialismo histórico dialético vigotskiano, porém, encontra-se em Karl Marx.
} 
aqui notamos o antidualismo, a integração completa entre cognição/emoção, personalidade/meio.

Particularmente com relação à educação, o autor bielorrusso chamava a atenção para os efeitos nefastos que a separação emoção/cognição provocava. O esforço da educação, na sua visão, se concentrava em manter a emoção o mais afastada possivel dos processos educacionais, os quais deveriam ter como único foco as questões cognitivas. Na contramão dessa diretriz (que, vale assinalar, é ainda hoje predominante), Vigotski afirmava que, no funcionamento psíquico humano, algumas funções psicológicas estão de tal maneira integradas que, em alguns casos, não seria possivel entender uma sem considerar a outra. ${ }^{5}$ Esse é o caso do pensamento em relação ao afeto:

Quem separou desde o início o pensamento do afeto fechou definitivamente para si mesmo o caminho para a explicação das causas do próprio pensamento, porque a análise determinista do pensamento pressupõe necessariamente a revelação dos motivos, necessidades, interesses, motivações e tendências motrizes do pensamento, que lhe orientam o movimento nesse ou naquele aspecto. De igual maneira, quem separou o pensamento do afeto inviabilizou de antemão o estudo da influência reflexa do pensamento sobre a parte afetiva e volitiva da vida psíquica [...] (Vigotski, 2009, p. 16).

Nesse sentido, ao contrário de tentar afastar a emoção da sala de aula, a educação deveria se valer desse mútuo condicionamento e tentar sempre atingir emocionalmente o aluno: "Antes de comunicar esse ou aquele sentido, o mestre deve suscitar a respectiva emoção do aluno e preocupar-se com que essa emoção esteja ligada a um novo conhecimento" (Vigotski, 2010a, p. 144).

A despeito desse atrelamento emoção/cognição, estudos mostram que à questão da afetividade não vem sendo dado o necessário cuidado na educação, notadamente nos seus níveis mais elevados do ensino, como é o caso das graduações (Lopes-Ribeiro, 2010). Podemos dizer o mesmo em relação à educação musical, pois, ainda que tangenciando diversos outros tópicos já amplamente discutidos, o tratamento dado à afetividade geralmente não passa de considerá-la um epifenômeno em algumas situações, cujas principais causas estão sempre em outro lugar. Considerando que as problemáticas na educação musical são multifatoriais, penso que o avanço na área implica a necessidade de olhar as questões sob vários ângulos. Desse modo, acredito ser importante neste momento revisitar alguns temas trazendo a questão da afetividade para o centro das preocupações, assumindo que não há ato educativo neutro, destituído de afeto e, mais do que isso, a qualidade das

\footnotetext{
5 Essa visão é corroborada por estudos neurológicos atuais, que mostram que as funções cerebrais não estão localizadas em um ponto específico do cérebro, como se acreditava anteriormente, mas espalhadas sistemicamente em vários pontos, de tal modo que se afetam mutuamente. Damásio (1996) apresenta um estudo específico sobre a relação entre a emoção e a tomada de decisões, no qual ele mostra como uma lesão em regiões cerebrais responsáveis pela emoção afeta capacidades racionais.
} 
relações afetivas instituídas nos processos de ensino será responsável, em grande medida, pelas possibilidades ou impossibilidades de aprendizagem. Com esse intuito, a seguir coloco alguns pontos que, surgidos a partir do exame de dados da referida pesquisa, a meu ver iluminam as práticas pedagógicas musicais e, com especial atenção, a formação do educador musical.

Antes, porém, considero necessário deixar claras algumas premissas: 1 - afetividade neste contexto diz respeito a dados concretos e passiveis de observação (motivações, interesses, gostos, escolhas, atitudes, etc.) e não a uma dimensão humana privada e inacessivel; 2 - a consideração pelas questões da afetividade não tem nada a ver com o professor procurar "ser bonzinho" ou "agradar os alunos", mas com coerência, capacidade de escuta, flexibilidade e autoavaliação constante; 3 - a afetividade não é um aspecto importante apenas quando se pensa na educação de crianças pequenas ou nas aprendizagens informais (locais onde geralmente ela é foco de atenção), mas é indissociável de qualquer processo educativo; 4 - estudos que tomam a afetividade como centro não buscam as verdades últimas sobre os fatos, mas os significados que esses fatos têm para os envolvidos.

\section{A PLURALIDADE DE EXPERIÊNCIAS MUSICAIS}

Partindo dos pressupostos acima delineados, o primeiro ponto que podemos levantar, e que de certa forma está contido em qualquer outro, diz respeito ao reconhecimento da existência do aluno em sua singularidade musical, a consideração e o respeito por dados subjetivos e marcas identitárias, fatores diretamente ligados à questão da afetividade.

Nas respostas colhidas na referida pesquisa sobre as experiências musicais pré-universidade, os alunos mostraram que o curso de licenciatura em música acolhe uma diversidade muito grande de trajetórias musicais. Recebemos desde músicos eruditos com dez anos de conservatório até autodidatas que tocam de ouvido diversos instrumentos e concentram seu conhecimento musical em algum gênero específico da música popular, por exemplo.

Mais do que a mera identificação e familiaridade com territórios musicais específicos, temos no curso diferentes modos de relação construída com a música, incluindo diferentes modos de processamento mental musical. De acordo com a psicologia vigotskiana, nossa psique é socialmente constituída nas experiências vividas e seu modo de funcionamento, embora tome como ponto de partida os determinantes biológicos, em grande medida acaba se moldando a partir de determinantes culturais, nas vivências a que se submete uma pessoa. Nesse sentido, músicos que aprendem música pela escrita possuem um modo de processamento musical que é muito distinto do modo adquirido num processo de aprendizagem eminentemente oral. Considerando o modelo de ensino conservatorial escriturístico que predomina nas graduações em música (Pereira, 2014), este segundo grupo de alunos está sempre em desvantagem em relação ao primeiro. Mesmo disciplinas que focam as habilidades aurais (que são o ponto forte desses alunos) não têm conseguido estabelecer uma ponte e fazer com que esses estudantes aprendam 
a reconhecer teoricamente o que muitos deles já sabem na prática. ${ }^{6} \mathrm{E}$, como essas disciplinas geralmente são base para quase tudo o que se segue no curso, o fracasso inicial acaba desencadeando uma série de fracassos posteriores. Um interesse pelos alunos nas suas singularidades musicais poderia dar origem a propostas de ensino que tomassem esse conhecimento prático como um facilitador e não um dificultador (às vezes impeditivo) no processo de aprendizagem.

É importante deixar claro que não se trata, especificamente nesse caso, da dicotomização "música erudita x música popular" nos currículos de formação em música. ${ }^{7}$ Essa polaridade, embora ainda mereça atenção, nesse contexto em análise não se mostrou um ponto nevrálgico, talvez porque se trate de uma instituição que possui um bacharelado em música popular já bastante consolidado e que procura conviver de maneira não hierárquica, e até certo ponto integrada, com o bacharelado em música erudita. O conflito que me pareceu mais evidente, por outro lado, de acordo com as falas dos participantes, diz respeito a uma insatisfação com os gêneros da música popular abordados no curso (restritos ao "jazz e seus derivados brasileiros", na fala de um aluno). Outros gêneros, "necessários ao educador musical", segundo alguns depoimentos (como "xote", "sertanejo", "rap", "pop”, "funk", "rock", entre outros citados), não são considerados. Dois fatos poderiam explicar essa ausência de um conflito explícito com a música de concerto, a vilã mais frequente nessas discussões. Em primeiro lugar, a música erudita foi citada por metade dos respondentes aos questionários como estando entre as suas preferências de escuta, o que revela que, nesse particular contexto estudado, essa é uma linguagem razoavelmente conhecida e apreciada. Em segundo, os alunos da licenciatura nessa instituição têm alguma liberdade de escolha em relação a seguirem disciplinas do currículo erudito ou popular, podendo, até certo ponto, se aprofundarem tanto numa linguagem quanto na outra. Ao contrário da oposição erudita/popular, nesse sentido, surpreendeu, por exemplo, o fato de um aluno que defende a legitimidade da música sertaneja ter destacado a importância do contato com música erudita no curso. Segundo esse aluno, ampliar suas referências estéticas estava lhe proporcionando ser um músico mais completo.

O problema a ser considerado, portanto, na minha visão, parece não dizer respeito a uma disputa entre diferentes estéticas musicais, mas ao modo de relação construída com a música que vem atrelado a essas estéticas. Para além da sonoridade musical em si, estamos falando de distintos processos de aprendizagem, contextos e formas de prática e escuta musical. Tudo isso, sob esse ponto de vista, afeta a maneira como os alunos receberão as disciplinas e coloca alguns grupos de alunos em desvantagem em relação a outros.

A consideração pela pluralidade de experiências musicais nas inúmeras possibilidades de encaminhamentos didáticos que, potencialmente, todas as

6 Questão discutida também em trabalho anterior (Moreira; Nassif, 2020).

7 Tema já exaustivamente debatido no campo da educação musical. Ver, por exemplo, Pereira (2014). 
disciplinas possuem, também diz respeito à afetividade e passa, nesse caso, pelo acolhimento, no ambiente de ensino formal, de saberes adquiridos em ambientes de aprendizagem informal. Esses saberes, de acordo com estudos no campo da educação, estiveram por muito tempo banidos das escolas, mas há várias discussões atualmente sobre a importância de sua valorização (Garcia; Alves, 2008), não obviamente em substituição ao conhecimento legitimado nas esferas formais do ensino, mas como um complemento ou mesmo canal de acesso a ele. ${ }^{8}$ É muito dificil se apropriar de qualquer conhecimento formal escolar quando não se é capaz de estabelecer conexões com a vida concreta fora da escola, com os saberes adquiridos em outros locais. Mais do que isso, são justamente os conhecimentos adquiridos assistematicamente no cotidiano em vivências concretas e carregadas de afeto que vão possibilitar a compreensão dos conhecimentos escolares, cuja característica principal é um alto grau de abstração (Vigotski, 2009). Então, seguindo esse raciocínio, as pessoas que tiveram oportunidade de desenvolver habilidades musicais de maneira informal em tese teriam mais bagagem, estariam mais aptas a entrar num certo universo sistematizado da música do que aquelas que iniciaram seus estudos diretamente nesse campo das abstrações. Essa é uma das premissas, vale lembrar, de projetos de ensino de música em ambientes formais que procuram recuperar, mesmo que de uma maneira um tanto artificial, modos de aquisição de habilidades musicais normalmente adquiridos em ambientes informais (Green, 2012), não apenas por razões de ordem técnica, mas também pelo aspecto afetivo e significativo envolvido nessas práticas. Assim sendo, a soma de diferentes abordagens na aproximação com a música talvez possa ser considerada a forma mais promissora de ensino musical.

Alguns dos nossos alunos da licenciatura que iniciaram seus estudos musicais fora dos modelos conservatoriais dispõem, por exemplo, de habilidades aurais de fazer inveja a músicos experientes (tiram músicas "de ouvido" e harmonizam "em tempo real" com muita facilidade). Esses saberes, porém, preciosos ao educador musical, têm muitas vezes um valor negado na universidade, o que leva ao sentimento de inadequação: ${ }^{9}$

No começo do curso cheguei a pensar que estudar música não era pra mim, principalmente por ter muita dificuldade em Percepção e Ritmica. Mesmo não tendo problemas com essas áreas pra minha prática profissional com música, eu pensava: "Se a Unicamp cobra de um músico essas habilidades (ler à primeira vista, transcrever ditados), quer dizer que são fundamentais e, se eu não consigo aprender do jeito que se cobra o aprendizado, não me enquadro."

\footnotetext{
8 Ao defender a entrada de outros saberes na universidade não estou de modo algum minimizando a importância do conhecimento sistematizado. Penso, ao contrário, que as universidades são locais por excelência de disseminação e reflexão sobre esse conhecimento, o que demanda o domínio dos meios escriturísticos. Essa é uma discussão, porém, que mereceria maior desenvolvimento, o que não será possível aqui.

9 Todos os trechos de fala destacados neste artigo foram extraídos de respostas dos questionários.
} 
Desmotivação:

[...] às vezes, sinto que minha capacidade não é muito valorizada, principalmente nas disciplinas relacionadas à formação musical, ainda sinto que há uma certa tendência a valorizar aspectos mais formais da música, ensinados, geralmente, em escolas tradicionais de música (que não foi a minha realidade). Isso afetou muito, principalmente no início (primeiro ano de faculdade), a minha motivação para o estudo.

Ou mesmo afastamento em relação ao curso:

Existe zero conexão do que eu faço com o que eu tive no curso. Aliás, eu desenhei minha vida cultural por conta, paralela à universidade [...]

Como consequência dessa desvalorização de determinados saberes e do sentimento de estranhamento e distanciamento em relação ao conhecimento oferecido, podemos dizer que passam a conviver no curso, inevitavelmente, dois currículos, o "oficial" e o "negado", "composto por tudo aquilo que não foi selecionado, normalizado, hierarquizado, centralizado" (Garcia; Alves, 2008, p. 74).

\section{AS PRÁTICAS MUSICAIS}

Os alunos que buscam o curso de licenciatura em música na instituição pesquisada em sua maioria o fazem com o objetivo principal de aprofundar conhecimentos musicais e não de tornarem-se educadores musicais. Nas respostas coletadas nesta pesquisa uma porcentagem relativamente grande de alunos $(36,1 \%)$ chegou a dizer que não tinha nenhum interesse particular em educação musical quando prestou o vestibular. Como docente da área pedagógica do curso, isso num primeiro momento me incomodou bastante, mas, posteriormente, analisando essa resposta em relação a todas as outras e ouvindo também os depoimentos dos entrevistados, essa impressão mudou. Parece-me, neste momento, que um forte interesse musical seja realmente a única razão plausível para alguém abrir mão da chance de ter profissões mais seguras, socialmente valorizadas e rentáveis. Muitos dos nossos alunos, inclusive, desistem de outros cursos para abraçar a música como profissão. O amor à música é o que os leva ao curso. O que os afasta?

Um aspecto mencionado pelos estudantes e que talvez esteja na raiz desse problema diz respeito às baixas oportunidades de prática musical ${ }^{10}$ oferecidas curricularmente. Quando prestam as provas de habilidades especificas em música no vestibular de ingresso, os candidatos à licenciatura precisam enviar um vídeo no qual executam uma peça em qualquer instrumento

\footnotetext{
10 Embora a noção de prática musical possa ser bastante ampla, neste tópico ela estará restrita às práticas instrumentais e vocais, pois esse foi o principal modo como a expressão foi usada pelos alunos.
} 
musical ou voz. Essa é a primeira prova e é eliminatória, ou seja, o curso tem como condição de ingresso ser instrumentista e/ou cantor. A primeira grande decepção, dessa forma, é se deparar com uma grade curricular na qual as aulas de instrumento serão poucas e, via de regra, oferecidas através de monitores. Essa questão foi mencionada, em momentos diferentes, por grande parte dos participantes. Abaixo temos alguns exemplos de falas.

[...] é muito ruim não ter aula de instrumento fornecida aos alunos de licenciatura, visto que nem todos conseguem pagar aulas particulares.

Eu sinto falta de aula de instrumento com os professores e não apenas os monitores.

Alunos de licenciatura não são cobrados quanto a tocar os instrumentos e nem mesmo a praticá-los. Isso desmotiva a própria cobrança de estudar e continuar com suas habilidades.

Esse quadro desvantajoso leva à sensação de que seus potenciais musicais não poderão ser desenvolvidos:

Tem que haver prática! Nós entramos no curso de licenciatura em pé de igualdade com os alunos do bacharelado, mas vamos ficando pra trás e sofrendo preconceitos, inclusive dos próprios professores [...].

A individualidade de cada ser humano, de acordo com a teoria histórico-cultural, é constituída a partir de suas vivências particulares, as quais são sempre atravessadas pela emoção. Essas vivências integram aspectos da personalidade e do meio (Vigotski, 2010b), o qual inclui também as relações sociais. Em outras palavras, a constituição de cada personalidade singular, incluindo a percepção de si mesmo, é social por natureza. Algumas das vivências mais importantes desses alunos foram perpassadas pela música, de tal maneira que, quando chegam à universidade, eles têm na música um forte traço de identidade e a principal razão da escolha do curso. O afastamento das práticas musicais, nesse sentido, parece ser uma das razões notáveis para o rápido declínio na motivação inicial.

A questão da motivação, aliás, tem sido um dos principais focos de atenção nas reflexões sobre o ensino superior em música, confirmando que esse é um problema não apenas na instituição pesquisada. Algumas teorias costumam dividir a motivação em intrínseca (processo de natureza espontânea, ligado a necessidades individuais e à valorização da atividade em si) e extrínseca (processo externo ao sujeito, ligado a possiveis consequências externas das ações). ${ }^{11}$ Embora essa organização de tipos de motivação traga algumas vantagens, do ponto de vista da teoria vigotskiana ela não se sustenta, uma vez que, assim como em qualquer outro conteúdo da psique humana,

${ }^{11}$ Cf. Araújo, Cavalcanti e Figueiredo (2010). 
entende-se que aspectos internos e externos estão sempre em jogo, numa relação dialética. Qualquer função psicológica especificamente humana, para Vigotski (2009), tem como regra geral iniciar-se externamente, em situações que de alguma forma envolvem relações sociais, e ser internalizada posteriormente, integrando-se à personalidade. Isso não seria diferente em relação às funções ligadas aos afetos. Nossos alunos tiveram experiências musicais profundamente motivadoras e isso os levou ao curso. Entretanto, por mais internalizado que esteja o desejo de fazer música, para que essa motivação se mantenha é necessário que as práticas musicais continuem e, mais do que isso, permitam vislumbrar um desenvolvimento musical. Não apenas nos constituimos socialmente, como precisamos do "outro" para nos percebermos e nos mantermos como somos. E, nesse sentido, as oportunidades de tocar e cantar, para além de todas as questões formativas envolvidas, seriam lugares por excelência de reafirmação das identidades musicais de cada um, sem as quais a profissão de educador musical perde completamente o sentido.

Num movimento pendular que vai de um extremo oposto ao outro e é típico das mudanças na educação, saímos de cursos de licenciatura em música que nada mais eram do que bacharelados aos quais se colavam algumas disciplinas pedagógicas para um curso, no caso da instituição pesquisada, em que a música quase não acontece. À parte das disciplinas teóricas ou teórico-práticas, que em geral apresentam o conhecimento musical de maneira bastante fragmentada, os alunos da licenciatura pouco contato têm, curricularmente falando, com música. Na fala de um aluno: "O curso me parece mais uma pedagogia com detalhes musicais, quando, a meu ver, deveria ser o oposto." Creio que talvez "o oposto" fosse retornar a modelos já superados. Em todo o caso, se, como bem afirma Penna (2007), "não basta tocar" para ser um bom professor de música, eu diria que tocar é necessário em um curso de formação de educadores musicais com o perfil dos ingressantes na instituição pesquisada, predominantemente de instrumentistas.

É importante destacar, com relação a essa questão, que tocar não implica necessariamente ter aulas individuais de instrumento. Em se tratando da formação de educadores musicais, as práticas instrumentais coletivas poderiam ser uma solução ao mesmo tempo possivel e mais interessante. O acesso garantido aos grupos musicais permanentes no departamento foi, inclusive, uma reinvindicação de alguns dos participantes da pesquisa.

Se considerarmos o fato de que muitos deles se formaram, antes da universidade, em contextos de ensino coletivo (como projetos sociais ou bandas de música, por exemplo), podemos ver aí também um forte indício motivacional para a música. De acordo com a psicologia vigotskiana, o estar junto com objetivos, motivos e interesses comuns num processo que faz "emergir mudanças no seu decorrer" (Prestes, 2018, p. 857) é um forte potencializador do desenvolvimento. O termo obschenie (sem tradução precisa em português) é usado por Vigotski para se referir a esses processos. Penso que os grupos musicais são locais permeados por obschenies e, nesse sentido, poderosos no que se refere às possibilidades de desenvolvimento musical, especialmente quando essas práticas são orientadas. 
Não encontrando oportunidades curriculares de prática musical coletiva, alguns alunos buscam-nas fora do currículo. Dos 36 respondentes ao questionário, 22 mencionaram pertencer a grupos musicais fora do departamento de música e apenas 7 disseram integrar grupos musicais do departamento de música. Se, por um lado, isso revela uma autonomia importante e mesmo, em alguns casos, um princípio de profissionalização, por outro lado demonstra que os grupos musicais existentes no departamento talvez estejam pouco abertos ao acolhimento dos alunos da licenciatura. Com exceção do coral, que é uma disciplina obrigatória, as práticas musicais coletivas oferecidas pelo curso de música são disciplinas eletivas para os licenciandos e, portanto, dependem de autorização do docente responsável. Não tendo garantido no curso o aprimoramento instrumental ou vocal, muitos desses alunos acabam tendo portas fechadas também no que diz respeito às práticas coletivas, completando-se assim o círculo meritocrático, no qual os menos privilegiados terão sempre menos oportunidades de aprendizagem e, portanto, de desenvolvimento musical: "É dessa forma que a meritocracia pode de fato produzir o fracasso que finge apenas refletir" (Elmgren, 2019, p. 436, tradução minha).

Ainda com relação a essa questão, é importante destacar que a hierarquia, que, de modo mais explícito ou mais velado, se estabelece entre alunos do bacharelado e da licenciatura, muitas vezes acaba fazendo com que os próprios licenciandos se autoexcluam das oportunidades oferecidas pelo curso, antes mesmo de terem o acesso negado. Em pesquisa realizada em escolas de música na Finlândia, Elmgren (2019) pôde constatar o modo como essas hierarquias se estabelecem entre estudantes de música, geralmente baseadas nas habilidades musicais percebidas, e, principalmente o modo como os estudantes mais altos nas hierarquias tendem a ganhar confiança e os mais baixos, a perder a confiança e a motivação. Não se trata, portanto, apenas de uma questão de oportunidades concretas, mas de autodesvalorização. Dito de outra forma, embora os alunos da licenciatura tenham efetivamente menos garantias curriculares de participação em grupos musicais, em grande medida muitos nem sequer irão tentar e preferirão buscar experiências musicais fora do currículo, em ambientes nos quais eles não se sintam julgados. Novamente aqui, podemos notar como a questão da afetividade vai direcionando as percepções e condutas dos alunos.

Nas palavras de uma aluna, os estudantes da licenciatura muitas vezes são vistos pejorativamente como aqueles que apenas irão "ensinar musiquinhas para criancinhas" e que, portanto, exercerão uma atividade tida como menor, o que justificaria uma formação musical rasa. Uma reflexão um pouco mais profunda, porém, tende a negar completamente esse estereótipo do educador musical como um profissional musicalmente mais despreparado do que um instrumentista, compositor ou regente, por exemplo. Considerando que esse profissional provavelmente terá que lidar com classes coletivas e diferentes contextos de ensino, penso que, ao contrário, o educador musical precisa ter uma formação musical sólida e diversificada. Enquanto para um instrumentista de orquestra, por exemplo, basta tocar bem o seu instrumento, o educador musical necessitará tocar preferencialmente mais de um instrumento, 
cantar razoavelmente, ser capaz de fazer harmonizações, pequenos arranjos, ter conhecimentos mínimos de regência, elaborar materiais didáticos musicais. Nesse sentido, uma formação musical ampla e consistente é absolutamente necessária e seria importante que os estudantes se sentissem amparados quanto a isso na instituição. É bem verdade que muitas vezes os alunos da licenciatura chegam com expectativas que não fazem parte da proposta do curso, como, por exemplo, a possibilidade de sairem licenciados no seu instrumento (isso foi mencionado algumas vezes nas respostas). Como a proposta do curso nessa instituição é a educação musical para contextos de ensino coletivo, especialmente a educação básica, alguns alunos acabam se decepcionando por não terem clareza quanto a isso. Em todo o caso, seja qual for o objetivo de uma licenciatura em música, reforço, sem a formação musical $^{12}$ nada será possível.

\section{CONSIDERAÇÕES FINAIS}

Neste trabalho foram apresentados alguns resultados de uma pesquisa em andamento sobre a percepção dos alunos de licenciatura em música em uma instituição pública sobre o curso e suas trajetórias pessoais no curso. Tomando como ponto de partida percepções de natureza subjetiva, as análises tiveram como centro a questão da afetividade e possibilitaram algumas reflexões objetivas sobre a formação do educador musical. Foram destacados dois aspectos: um mais estrutural, que diz respeito às oportunidades de prática musical oferecidas pelo currículo, e outro de cunho mais didático, que abordou a pluralidade de experiências musicais prévias que caracteriza o perfil discente do curso em sua relação com algumas disciplinas.

Em acordo com o referencial teórico-metodológico assumido, as análises apresentadas tomaram como premissa a unidade afeto-cognição na constituição da psique humana e permitiram ver possiveis indícios de problemas relativos aos processos de aprendizagem que ocorrem no contexto pesquisado. Procurou-se acessar, nessa etapa da pesquisa, uma primeira camada de significados musicais construídos pelos participantes e, com isso, foi possivel levantar questões que estão profundamente ligadas à afetividade na perspectiva vigotskiana, como a desmotivação, o sentimento de inadequação, o estranhamento em relação ao conhecimento oferecido pelo curso (especialmente à forma como a música é abordada) e a desconsideração pelas identidades musicais dos graduandos (aí incluídas muitas de suas vivências musicais anteriores). A intenção não foi tentar capturar, como ponto de partida, a realidade "em si", mas a realidade "para si", entendendo que os modos como os alunos percebem o curso e se percebem no curso afetam profundamente suas possibilidades ou impossibilidades de desenvolvimento musical e suas disposições para seguir ou não no caminho inicialmente desejado. Também não

\footnotetext{
12 As características das licenciaturas em música podem ser muito diferentes em cada lugar. Nesse sentido, em todas as questões abordadas neste artigo não há qualquer intenção de generalização para além da instituição pesquisada.
} 
foi intenção substituir ou minimizar investigações de questões semelhantes que partam de outras bases teóricas, mas apenas chamar a atenção para a centralidade da afetividade na educação, ampliando assim as possibilidades de análise de fenômenos tão complexos, como são os educacionais.

Como reflexão final, gostaria de enfatizar a necessidade de que, em qualquer contexto de ensino de música, os professores olhem para seus alunos, interessem-se pelas suas relações construídas com a música e através da música. Temos repetido quase como um mantra na educação musical que é necessário considerar as experiências musicais prévias dos alunos. Esse é um tópico praticamente obrigatório nas aulas de pedagogia da música. Entretanto, parece-me que todo esse discurso fica completamente vazio se os futuros educadores musicais não tiverem suas experiências musicais consideradas no seu próprio processo formativo. Talvez não seja necessário recorrer a teorias psicológicas para saber que modelos e ações são muito mais potentes do que discursos e, uma vez que esses estudantes não estão tendo suas vivências musicais anteriores incluídas de alguma maneira no curso, há uma forte chance de que eles não consigam saber como fazer isso, futuramente, com seus próprios alunos.

\section{REFERENCIAS}

ARAÚJO, Rosane Cardoso de; CAVALCANTI, Célia Regina Pires;

FIGUEIREDO, Edson. Motivação para prática musical no ensino superior: três possibilidades de abordagens discursivas. Revista da Abem, Porto Alegre, v. 24, p. 34-44, 2010. Disponivel em: http:/ / abemeducacaomusical. com.br/revista_abem/ed24/revista24_artigo4.pdf. Acesso em: 10 abr. 2021.

ARROYO, Margarete. Culturas juvenis - Música e escola: o que a literatura problematiza. In: CONGRESSO DA ASSOCIAÇÃO NACIONAL DE PESQUISA E PÓS-GRADUAÇÃO EM MÚSICA, 16., 2006, Brasília. Anais [...]. Brasília: Anppom, 2006. p. 61-67. Disponivel em: https://antigo.anppom.com.br/ anais/anaiscongresso_anppom_2006/CDROM/COM/01_Com_EdMus/ sessao03/01COM_EdMus_0301-040.pdf. Acesso em: 10 abr. 2021.

DAMÁSIO, António R. O erro de Descartes: emoção, razão e o cérebro humano. São Paulo: Companhia das Letras, 1996.

ELMGREN, Heidi. Merit-based exclusion in Finnish music schools. International Journal of Music Education, Los Angeles, v. 37, n. 3, p. 425439, 2019.

GARCIA, Regina Leite; ALVES, Nilda. Atravessando fronteiras e descobrindo (mais uma vez) a complexidade do mundo. In: ALVES, Nilda; GARCIA, Regina Leite (org.). O sentido da escola. 5. ed. Petrópolis: DP et Alii, 2008. p. 65-89. 
GREEN, Lucy. O ensino de música em si, para si mesma e para "outra" música: uma pesquisa atual em sala de aula. Revista da Abem, Londrina, v. 20, n. 28, p. 61-80, 2012. Disponivel em: http://www. abemeducacaomusical.com.br/revistas/revistaabem/index.php/ revistaabem/article/viewFile/104/87. Acesso em: 10 abr. 2021.

LEITE, Sérgio Antônio da Silva. Afetividade nas práticas pedagógicas. Temas em Psicologia, [s. l.], v. 20, n. 2, p. 355-368, 2012. Disponivel em: http:// pepsic.bvsalud.org/pdf/tp/v20n2/v20n2a06.pdf. Acesso em: 10 abr. 2021.

LOPES-RIBEIRO, Marinalva. A afetividade na relação educativa. Estudos de Psicologia, Campinas, v. 27, n. 3, p. 403-412, 2010. Disponivel em: https:// www.scielo.br/scielo.php?pid=S0103-166X2010000300012\&script=sci abstract\&tlng=pt. Acesso em: 10 abr. 2021.

MOREIRA, Francieli Fernanda; NASSIF, Silvia Cordeiro. Tensões e contradições entre herança cultural e desempenho acadêmico em um curso de Licenciatura em Música no Brasil. Revista Portuguesa de Educação Musical, Braga, n. 146, p. 63-72, 2020.

PENNA, Maura. Não basta tocar? Discutindo a formação do educador musical. Revista da Abem, Porto Alegre, v. 16, p. 49-56, 2007. Disponivel em: http:/ / www.abemeducacaomusical.com.br/revistas/revistaabem/index. $\mathrm{php} /$ revistaabem/article/view/291. Acesso em: 10 abr. 2021.

PEREIRA, Marcus Vinícius Medeiros. Licenciatura em Música e habitus conservatorial: analisando o currículo. Revista da Abem, Londrina, v. 22, n. 32, p. 90-103, 2014. Disponivel em: http://www.abemeducacaomusical. com.br/revistas/revistaabem/index.php/revistaabem/article/view/464. Acesso em: 10 abr. 2021.

PINTO, Alexandrina. Motivação para o estudo de música: factores de persistência. Revista Música, Psicologia e Educação, Porto, n. 6, p. 33-44, 2004. Disponivel em: https://parc.ipp.pt/index.php/rmpe/article/ view/2429. Acesso em: 10 abr. 2021.

PRESTES, Zoia. Obschenie e a teoria histórico-cultural. Educação em Foco, Juiz de Fora, v. 23, n. 3, p. 851-874, 2018. Disponivel em: https:// smeduquedecaxias.rj.gov.br/smeportal/wp-content/uploads /2020/07/ OBSCHENIE-E-A-TEORIA-HIST\%C3\%93RICO-CULTURAL.pdf. Acesso em: 10 abr. 2021.

RAMALHO, Elba Braga. Um currículo abrangente, sim. Revista da Abem, Porto Alegre, v. 8, p. 47-51, 2003. Disponivel em: http:/ / abemeducacaomusical.com.br/revista_abem/ed8/revista8_artigo8.pdf. Acesso em: 10 abr. 2021. 
RAMOS, Danilo; TONI, Anderson. Reflexões sobre os cursos de Música da UFPR e as expectativas dos alunos ingressos em 2016. In: ENCONTRO REGIONAL SUL DA ABEM, 17, 2016, Curitiba. Anais [...]. Curitiba: Abem, 2016. Disponivel em: http:/ / abemeducacaomusical.com.br/conferencias / index.php/xviiregsul/regs2016/paper/view/1808. Acesso em: 10 abr. 2021.

REIS, João Gomes; DUARTE, Pedro. O currículo, a educação musical e as realidades individuais de cada estudante: um ensaio em defesa da inclusão cultural no ensino de música. Revista da Abem, v. 26, n. 41, p. 5-20, 2018. Disponivel em: http://www.abemeducacaomusical.com.br/revistas / revistaabem/index.php/revistaabem/article/view/765. Acesso em: 10 abr. 2021.

SANTOS, Gabriel Matsudo dos; CERNEV, Francine Kemmer. A motivação para aprender música no ensino superior: reflexões a partir de um curso de Licenciatura em Música. Revista da Abem, v. 27, n. 42, p. 149-162, 2019. Disponivel em: http:/ / abemeducacaomusical.com.br/revistas/revistaabem/ index.php/revistaabem/article/view/822. Acesso em: 10 abr. 2021.

SOUZA, Jusamara. Educação musical e práticas sociais. Revista da Abem, Porto Alegre, v. 10, p. 7-11, 2004. Disponivel em: http:// abemeducacaomusical.com.br/revistas/revistaabem/index.php/ revistaabem/article/view/356. Acesso em: 10 abr. 2021.

TOASSA, Gisele. Emoções e vivências em Vigotski. Campinas: Papirus, 2011.

VIGOTSKI, Lev Semenovich. Teoría de las emociones: estúdio históricopsicológico. Madrid: Ediciones Akal, 2004.

A construção do pensamento e da linguagem. 2. ed. São Paulo: Martins Fontes, 2009.

A educação no comportamento emocional. In: VIGOTSKI, Lev Semenovich. Psicologia pedagógica. 3. ed. São Paulo: Martins Fontes, 2010a. p. 127-147.

Quarta aula: a questão do meio na pedologia. Psicologia USP, São Paulo, v. 21, n. 4, p. 681-701, 2010b. 
Silvia Cordeiro Nassif é doutora em Educação pela Universidade Estadual de Campinas (Unicamp), graduada em Letras e em Música pela mesma instituição. Trabalhou como docente na Universidade de São Paulo (USP) de 2007 a 2014. Atualmente é docente do Departamento de Música do Instituto de Artes da Unicamp, atuando na área de Educação Musical do curso de Licenciatura em Música e como orientadora no Programa de Pós-Graduação em Música dessa instituição. Coordenadora do Grupo de Pesquisa Música, Linguagem e Cultura (MUSILINC/ CNPq), desenvolve pesquisas em educação musical na sua interface com a linguagem, a cultura e o desenvolvimento humano. Tem artigos publicados em alguns dos mais importantes periódicos de música e de educação do Brasil. https://orcid.org/0000-0002-9445-5342 